Vittalle - Revista de Ciências da Saúde v. 30, n. 1 (2018) 72-83
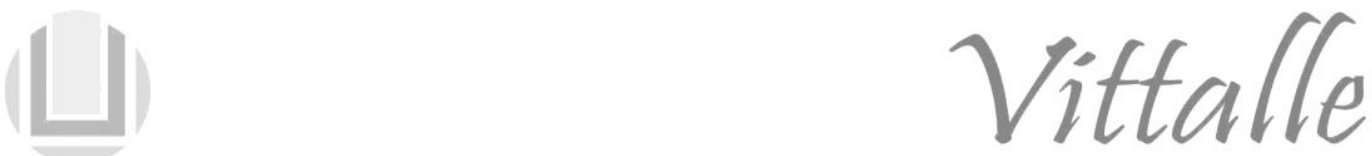

\title{
Prescrição fitoterápica por nutricionistas: percepção e adequação à prática
}

\author{
Ana Bolena de Luna Siqueira ${ }^{a, *}$ e René Duarte Martins ${ }^{\mathrm{b}}$
}

${ }^{a}$ Centro Universitário do Vale do Ipojuca, Caruaru, PE, Brasil

${ }^{\mathrm{b}}$ Centro Acadêmico de Vitória, Universidade Federal de Pernambuco, Vitória de Santo Antão, PE, Brasil

Histórico do Artigo

Recebido em:

18/11/2018

Aceito em:

$21 / 03 / 2018$

\section{Palavras-chave:}

Fitoterapia;

plantas medicinais;

habilidade;

pesquisa qualitativa.

Keywords:

Phytotherapy; medicinal plants;

Aptitude;

qualitative research.

\begin{abstract}
RESUMO
$\mathrm{O}$ aumento na utilização de plantas medicinais, através da fitoterapia tem crescido na população, ampliando a prescrição por profissionais da área de saúde. Após a autorização do Conselho Federal de Nutrição, por meio da resolução número 402/2007, os nutricionistas agregaram os fitoterápicos ao tratamento dietoterápico de forma complementar. O objetivo deste foi caracterizar a prescrição fitoterápica por nutricionistas e seus sentimentos frente a essa habilitação. Adotou-se um desenho qualitativo, utilizando roteiro de entrevistas semiestruturadas, aplicado aos nutricionistas atuantes na capital de Pernambuco, através da técnica "bola de neve" e amostragem por critério de saturação da informação. A análise de conteúdo dos depoimentos foi feita a partir do modelo de categorias temáticas de Bardin. Verificou-se que boa parte dos entrevistados concluiu a graduação de Nutrição há pelo menos 11 anos, metade não realizou curso de aperfeiçoamento em fitoterapia, mas a maioria realiza prescrição para os casos de obesidade, como moderador de apetite, ansiedade entre outros. Os motivos para prescreverem ou não, vão desde a falta de conhecimento, passando pela ausência do tema na graduação até a credibilidade do produto, envolvendo sentimentos de segurança e outras inquietações. Conclui-se que alguns integrantes do grupo estudado não estão preparados para prescrever com segurança. Os dados sugerem uma possível confusão quanto à prescrição e à indicação, conforme resoluções no $402 / 2007$ e n ${ }^{\circ} 525 / 2013$, e pouca nitidez quanto à adequada prescrição na prática. Tornam-se importantes mais estudos sobre a prescrição de fitoterápicos pelos nutricionistas, pois investigará, após o conhecimento e aprovação de resoluções mais recentes, a prática, a adequação e a percepção desses profissionais.
\end{abstract}

Phytotherapeutic prescription by nutritionists: perception and suitability to practice

\section{ABSTRACT}

The increase in the use of medicinal plants, through phytotherapy has grown in the population increasing the prescription by health professionals. After the authorization of the Federal Nutrition Council, through resolution number 402/2007, nutritionists added herbal medicines to complementary dietary therapy. The objective of this study was to characterize the phytotherapeutic prescription of nutritionists and their feelings regarding this qualification. A qualitative design was adopted using a semi-structured interview script, applied to nutritionists working in the capital of Pernambuco, using the "snowball" technique and sampling by information saturation criterion. The analysis of the content of the testimonies was made from the model of thematic categories of Bardin. It was verified that a good part of the interviewees concluded the graduation of Nutrition for at least 11 years, half did not carry out an improvement course in phytotherapy, but most prescribes for cases of obesity, as moderator of appetite, anxiety among others. The reasons to prescribe or not, range from the lack of knowledge, from the absence of the subject in the graduation to the credibility of the product, involving feelings of security and other concerns. It is concluded that some members of the group studied are not prepared to prescribe safely. The data suggest a possible confusion regarding the prescription and indication, according to resolutions $n^{\circ} 402 / 2007$ and $n^{\circ}$ $525 / 2013$, and little clarity as to the appropriate prescription in practice. Further studies on the prescription of herbal medicines by nutritionists are important, as they will investigate, after the knowledge and approval of more recent resolutions, the practice, adequacy and perception of these professionals.

\footnotetext{
* Autor correspondente: anabluna@gmail.com (A. B L. Siqueira)
} 


\section{Introdução}

Por milhares de anos, as plantas medicinais vêm sendo usadas para tratamento de doenças. Existem relatos dessa atividade para fins terapêuticos desde 3000 anos a.C. na obra Pen T'sao do chinês Shen Nung. Por mais de 14 séculos, utilizou-se como referência o Tratado de matéria médica, cujo conteúdo continha descrições sobre cerca de 600 plantas medicinais, elaborado pelo botânico grego Pedanios Dioscorides no ano de 78 d.C. No Egito, antigos papiros mostram que, a partir de 2000 a.C., muitos médicos faziam uso das plantas como remédio e consideravam a doença como resultado de causas naturais e não como consequência dos poderes de espíritos maléficos. Já no Papiro Ebers, que data de cerca de 1500 a.C., cerca de 700 drogas diferentes foram mencionadas, incluindo extratos de plantas, metais como chumbo e cobre, e venenos de animais de várias procedências (1).

O conhecimento adquirido sobre essas espécies, seus usos, indicações e manejo são uma herança dos antepassados, que, de forma tradicional, têm passado suas sabedorias de geração a geração, desde os tempos mais remotos até os dias atuais (2), havendo registros do uso de plantas medicinais de forma terapêutica, desde a antiguidade, pelas civilizações da China, Índia, Egito e Grécia (3).

Tem-se percebido, cada vez mais, o uso e a aceitação dos fitoterápicos pela população. Fatores que podem justificar tal crescimento envolvem os avanços nos estudos científicos que proporcionaram produção de fitoterápicos seguros e eficazes, bem como a busca dos indivíduos por terapias alternativas menos agressivas nos atendimentos primários da saúde (4). A utilização dos fitoterápicos e de plantas medicinais emerge como uma opção de tratamento acessível e ativo nas suas propriedades e que atende às necessidades terapêuticas da população usuária, principalmente diante de doenças infantis prevalentes. Associa-se a crescente utilização das plantas medicinais pelos cidadãos ao baixo custo e ao fácil acesso a esses produtos (5).

Canigueral \& Vila (6) definem Fitoterapia como a ciência que estuda a utilização dos produtos de origem vegetal com finalidade terapêutica, ou seja, para prevenir, atenuar ou curar um estado patológico. Fitoterápicos são produtos obtidos de plantas medicinais, ou de seus derivados, exceto substâncias isoladas, com finalidade profilática, curativa ou paliativa (7). Plantas medicinais são definidas como todo e qualquer vegetal que possui, em um ou mais órgãos, substâncias que podem ser utilizadas com fins terapêuticos ou que sejam precursores de fármacos semissintéticos (8).

De acordo com Tomazzoni (9), "A busca de outras possibilidades terapêuticas, entre elas a fitoterapia, para resolução dos problemas de saúde, ou seja, a cura de doenças, demonstra que essa prática, além da ação terapêutica que tem sido comprovada em muitas das plantas utilizadas popularmente, representa parte importante da cultura de um povo e precisa ser valorizada".

Embora seja uma prática antiga, trabalhos científicos são recentes e o uso dos fitoterápicos sem conhecimento específico pode gerar problemas à saúde. Para Balbino \& Dias (10), as plantas medicinais, devido à interação com alimentos, medicamentos ou características dos pacientes como idade, condições fisiológicas, entre outros, podem desencadear efeitos adversos pelos seus próprios constituintes.

A partir da implantação da Resolução do Conselho Federal de Nutricionistas $n^{\circ} 402$, de 6 de agosto de 2007, informando que é permitida a todo profissional nutricionista a prescrição de medicamentos fitoterápicos de uso oral, sejam esses a droga vegetal in natura ou em suas diversas formas farmacêuticas, o campo de atuação para esse profissional foi ampliado (11).

Diante da Resolução do CFN e considerando as recentes políticas nacionais, entre elas, 
a Política Nacional de Práticas Integrativas e Complementares (12) e órgãos internacionais, em especial a Organização Mundial da Saúde, que vêm reconhecendo, valorizando e incentivando o uso de plantas medicinais e fitoterápicos dentro dos serviços públicos de saúde, bem como a portaria do Ministério da Saúde no 971 de 03/05/2006 (13), que inclui essa utilização como caráter de atuação multidisciplinar, enfatizando a necessidade dos debates acerca dos questionamentos referentes à prática do nutricionista relacionada à prescrição dos fitoterápicos, desafios e inseguranças desses profissionais, que podem levar a entraves no exercício de sua atividade.

No exposto, justifica-se a presente pesquisa, a qual teve por objetivo caracterizar o perfil de profissionais nutricionistas que prescrevem fitoterápicos, caracterizar essa prática e conhecer as causas que motivam ou desmotivam a prescrição de fitoterápicos por nutricionistas, bem como seus sentimentos e sua percepção frente a essa habilitação, a fim de que possa contribuir para adesão desse tema no currículo acadêmico, para o processo de formação de recursos humanos, incentivo ao desenvolvimento científico em busca de novos elementos com finalidades terapêuticas e, colaborar para que o nutricionista atue com mais segurança.

\section{Materiais e métodos}

Foi realizada uma pesquisa qualitativa, descritiva. A pesquisa qualitativa está voltada para a investigação de valores, percepções, atitudes e motivações do público pesquisado, com propósito de compreendê-los, sem preocupação estatística, além dos dados serem de caráter interpretativo (14). Trabalha-se, ainda, com significados, crenças, motivos, aspirações, valores e atitudes, destinando-se a uma aproximação com o objeto de estudo (15).

A pesquisa ocorreu em duas fases, a primeira ocorreu após aprovação, pelo Comitê de Ética em Pesquisa do departamento de ciências da Saúde/UFPE, sob o parecer de $\mathrm{n}^{\circ}$ 368.752, em 23/08/2013, com a aplicação de um questionário elaborado pela própria pesquisadora e realização de entrevista piloto (contemplando dados que caracterizassem o pesquisado, atividade de prescrição e indicações dos fitoterápicos, bem como uma abordagem qualitativa, com um roteiro constituído por 9 questões) também elaborada pela pesquisadora, por meio da qual se verificou a necessidade de realizar adaptações de modo a garantir a validade e a objetividade da investigação, além de favorecer o confronto entre técnicas de recolha de dados.

$\mathrm{Na}$ segunda fase, foram realizadas oito entrevistas, em oito encontros, com oito nutricionistas uma vez que se utilizou a saturação das informações para chegar a uma amostragem, com nutricionistas atuantes, predominantemente, na área clínica ou saúde pública, inscritas no Conselho Regional de Nutrição na região 6 (CRN6), que trabalhassem ou tivessem vínculo empregatício em cidades de Pernambuco, de ambos os sexos e sem limite de idade, sendo esses os critérios de inclusão. Foram excluídos todos que não se encaixassem nesses critérios e que não fossem sugeridos pelos pesquisados ao término da entrevista. Esse modelo de amostragem trata-se de fenômeno que ocorre quando, após certo número de entrevistas, o entrevistador começa a ouvir, de “novos' entrevistados, relatos muito semelhantes àqueles que já foram ouvidos, caracterizando uma rarefação de informações novas (16); desse modo, a preocupação com o "n" torna-se impertinente, e o número de sujeitos é definido em campo (17). A coleta dos dados foi realizada pela pesquisadora entre os meses de Março e Abril de 2014, em local reservado e pré-estabelecido pelos pesquisados já que se utilizou a técnica qualitativa denominada "Bola de Neve", após leitura e assinatura do Termo de 
Consentimento Livre Esclarecido. A técnica "bola de neve" (SNOWBALL) também conhecida por cadeia de referência ou de informantes (18) é uma forma de amostra não probabilística ${ }^{1}$, em que um pesquisado inicial indica outro, que, por sua vez, indica novo participante, de modo sucessivo, por julgar que esse outro possua informações que colaborem para a pesquisa (19). Os pesquisados foram abordados por contato telefônico e o nome do primeiro entrevistado foi indicado pelo último nutricionista participante do teste piloto. Os outros foram sugeridos pelos demais pesquisados ao término de cada entrevista. Foi resguardado, ainda, o sigilo e a privacidade das falas dos entrevistados, conforme resolução 196/96 (20), revogada e substituída pela Resolução do Conselho Nacional de saúde (CNS) N466/2012 (21). Os próprios participantes preencheram o questionário composto pelas variáveis utilizadas no teste piloto, após o ajuste, contendo perguntas como: sexo, idade, titulação, área de atuação, instituição de egresso, tempo de conclusão da graduação, além de perguntas sobre prescrição de fitoterápicos, inclusive, caso realizassem prescrição, para quais condições clínicas e conhecimento sobre resoluções do CFN envolvendo fitoterápicos. Posteriormente, a pesquisadora realizou a entrevista guiada por três questões norteadoras: 1 - Por que você prescreve ou não prescreve fitoterápicos? 2 - Como você se sente frente a essa habilitação de prescrever em fitoterapia? 3 - Como você vê a prescrição de fitoterápicos pelo nutricionista? Tais questões norteadoras foram elaboradas com finalidade de ajudar a atingir o objetivo proposto, complementadas com outras, aprofundando aspectos que emergiram durante a interação estabelecida com os participantes. Subsequente à fase de tratamento com a transcrição das entrevistas, as quais foram gravadas na sua totalidade, realizou-se a análise de conteúdo dos depoimentos por meio de grelhas de análise que permitiram a leitura comparativa, seguindo da definição das categorias associada à técnica de análise temática descrita por Bardin (22). Ou seja, a partir das respostas advindas das questões norteadoras, realizou-se leitura flutuante, que implica conhecer, inicialmente, o material e criar familiaridade, seguido da descrição analítica do material, análise do conteúdo, análise comparativa e finalizando com a interpretação dos resultados, feita na Análise de Conteúdo, por meio da inferência, resultando na definição das categorias temáticas.

A pesquisadora realizou treinamento e adquiriu conhecimentos do tipo de pesquisa por meio da disciplina Métodos Qualitativos Aplicados à Ciência da Saúde, a fim de não ter influência nas respostas dos pesquisados. Não houve perda de dados.

\section{Resultados}

Com relação ao perfil dos oito indivíduos pesquisados e que inserem fitoterápicos como complementação dietoterápica (seis participantes), foi revelado que todos eram do sexo feminino, a maioria está na faixa etária entre 31 e 40 anos, com título de especialista, atuando, predominantemente, na área clínica, em hospitais particulares, hospitais públicos e clínicas particulares e egressos de uma Instituição Pública de Ensino Superior. Metade dessas pessoas concluiu o curso há, pelo menos, 11 anos.

Foi constatado ainda que quatro participantes não realizaram curso de aperfeiçoamento em fitoterapia, cinco informaram não conhecer a resolução 402/2007 do CFN e três já ouviram falar ou leram algo. Sete relataram que não tiveram disciplinas na graduação que subsidiaram a prescrever fitoterápicos.

Quanto à preferência em prescrever plantas medicinais, drogas vegetais e/ou

\footnotetext{
${ }^{1}$ Amostra não probabilística é aquela em que os elementos da amostra são compostos de forma intencional, acidental ou por quotas; elas não garantem certeza quanto à representatividade do universo (BARROS; LEHFELD, 2002) BARROS, Aidil de Jesus Paes de; LEHFELD, Neide Aparecida de Souza. Projeto de Pesquisa: proposta metodológica. 13. Ed. Petrópolis: Vozes, 2002.
} 
medicamentos fitoterápicos, as plantas medicinais e medicamentos fitoterápicos foram os produtos mencionados.

Para quem realizava prescrição/orientação fitoterápica (plantas medicinais), as condições clínicas mencionadas foram para os casos de obesidade (emagrecedor), moderador de apetite, ansiedade, compulsão, insônia, dispepsia, retenção hídrica, constipação/diarreia, má digestão, hepatoprotetor. O chá verde (Camellia sinensis), a alcachofra (Cynara scolymus), o cardo mariano (Silybum marianum (L.) Gaertn), a grifonia (Griffonia simplicifolia) e o boldo (Plectranthus barbatus Andr.) foram os itens mencionados como os mais prescritos. Revistas/artigos científicos e os livros específicos foram fontes de informação que baseavam a prescrição dos fitoterápicos.

Nas entrevistas, as respostas das perguntas norteadoras passaram por análise de conteúdo, segundo as perspectivas de Badin (22) e, ao término, por meio de inferências, foram definidas as categorias temáticas mencionadas a seguir, acompanhadas de falas dos indivíduos que caracterizam essas temáticas, não sendo mencionados trechos de todas as pessoas participantes uma vez que se repetiam ou se assemelhavam.

Temática 1. Peculiaridades que motivam ou desmotivam a prescrição fitoterápica

\subsection{Ausência do tema na graduação}

O tema sobre fitoterápicos tem sido introduzido à grade curricular nos últimos anos, contribuindo para maior conhecimento, embora ainda não seja motivo para prescrevêlos. A ausência desse tema na graduação, de modo efetivo, e que viesse a deixar o profissional preparado para prescrever, é mencionado nas falas:

Entrevistada 6 “... não prescrevo hoje fitoterápico por falta de conhecimento realmente no que a gente pode prescrever..."

Entrevistada 5 “... realmente, a gente fica um pouco desabilitado por não ter essas condições na cadeira, na prática da faculdade..."

\subsection{Conhecimento científico}

Embora o pouco conhecimento ou a ausência do tema na grade curricular tenha sido mencionado, ainda assim a prescrição de fitoterápicos é realizada desde que haja o embasamento científico, agregado aos resultados favoráveis:

\footnotetext{
Entrevistada 1 “... eu prescrevo porque eu já conheço da literatura e porque também é, outras colegas que tiveram resultados positivos me passaram informação..."

Entrevistada 7 “... minha prescrição é limitada porque, na verdade, meu conhecimento é um pouco limitado...

"...eu vou me baseando em evidências científicas..."
}

\subsection{Crença nos fitoterápicos}

A credibilidade do produto ou o fato de serem menos agressivos também foram apontados como um dos motivos em prescrever fitoterápicos, conforme trechos abaixo:

Entrevistada 3 “... é necessário entrar sim, em momentos pontuais como esse, pra que o problema seja ou amenizado o mais rápido possível, ou até, porque não, resolvido..." 
A. B. de L. Siqueira et al./ Vittalle v. 30, n. 1 (2018) 72-83

Entrevistada 4: “... eu vejo os resultados e acredito na sinergia entre o organismo e a planta viva..."

Entrevistada 5: “... eu acho interessante a gente ir mais pra essa parte, entre aspas, natural, do que ficar numa medicação que eles acabam se acostumando por vários anos..."

Temática 2. Importância de especialização para prescrever fitoterápicos com segurança

\subsection{Necessidade de ampliar a formação para prescrever com segurança}

O conceito da necessidade de maiores estudos ou especialização foi verificado em trechos ressaltados por alguns nutricionistas, inclusive o conhecimento da mais recente resolução sobre o tempo estipulado para obter tal aprimoramento, conforme as falas a seguir:

Entrevistada 2 “... eu farei a especialização em fitoterapia não é porque eu sei que já chegou uma nova lei que a gente tem uma data " $x$ " para prescrever até, assim, sem especialização..."

Entrevistada 5 “... eu acho que essa habilitação a gente teria que conversar um pouco mais a respeito dela pra saber, realmente, até onde pode o nutricionista e o que a gente poderia fazer..."

“... tem que buscar especialização..."

Temática 3. Sentimentos frente à prescrição de Fitoterápicos

\subsection{Segurança/Insegurança para prescrever fitoterápicos}

Quando questionados sobre como se sentiam diante da atribuição de prescrever fitoterápicos, uma variedade de sensações foi aludida, como tranquilidade, segurança (uma vez que estivessem embasados), insegurança, felicidade, além de se sentirem incapacitados. Tais relatos são verificados nas falas:

Entrevistada 2 “... não me sinto segura no momento e só realmente prescrevo quando tenho segurança...”

Entrevistada 4 “... Hoje eu não me sinto tão capacitada quanto eu gostaria, eu gostaria de me capacitar mais...”

Entrevistada 8: “... Olhe, eu me sinto muito tranquila, porque, assim, sempre estou procurando informação com relação à conduta..."

Entrevistada 6: “... Eu fico animada, eu acho que é uma nova área...”

A mistura, em certos momentos, de segurança com insegurança é descrita na fala da entrevistada 7:

\footnotetext{
“... tem muito embasamento científico para uns fitoterápicos hoje que tem uma relevância bem importante de controle de sintomatologia na área de oncologia, então eu me sinto bem segura..."

"eu me sinto bem insegura por isso, eu já li vários artigos, inclusive, uso e prescrição de fitoterápicos de forma inadequada"
} 
Temática 4. Perspectivas da Fitoterapia na visão do nutricionista 4.1. Apoio na abordagem nutricional

Algumas entrevistadas consideraram que o tema sobre fitoterápicos é amplo e a vinda da Resolução abriu um novo campo, que veio para apoiar a conduta nutricional:

Entrevistada 2 “... acho super importante, como respondi na segunda questão, que é, faz parte também da nossa abordagem nutricional...”

Entrevistada 8 “... é mais uma ferramenta de trabalho... ... não deixa de ser importante pra gente que atua."

\subsection{Cautela ao prescrever em Fitoterapia}

Um ponto de destaque foi que, embora considerem uma área promissora, uma ferramenta de trabalho interessante, a cautela é indicada, inclusive, para que não haja perda dessa atribuição ou da credibilidade:

Entrevistada 4 “... é uma ferramenta hoje na nutrição que toda nutricionista deveria usar, mas com responsabilidade, a gente não pode deixar de pensar na responsabilidade que a gente tem com a vida do nosso paciente..."

Entrevistada 8 “...se a gente não souber trabalhar melhor essa ferramenta...” “... talvez a gente corra o risco de perder credibilidade..."

\subsection{Novo ramo com Consolidação da profissão}

Na percepção de algumas pesquisadas, outro ponto ressaltado foi que ainda se vê essa atividade como um campo de conhecimento reduzido, embora de grande importância e que vem para consolidar a profissão:

\footnotetext{
Entrevistada 1 “... tá muito reduzido ainda... ... não é muito explorado... ... precisa estudar muito pra poder fazer com mais segurança...”

Entrevistada 4 “... uma ferramenta maravilhosa que o nutricionista disponibiliza..."

Entrevistada 6 “... uma vitória pra gente, novos ramos da nutrição...”
}

\section{Discussão}

No ano de 2005, o CFN demonstrou o perfil da "identidade" profissional do nutricionista, o qual informava que $41,7 \%$ estavam atuando em nutrição clínica seguido de $32,2 \%$ em alimentação coletiva e 9,4\% em ensino (docência). Anunciava, ainda, que $47,4 \%$ dos nutricionistas brasileiros tinham cursado ou estavam realizando cursos de especialização, 9,4\% tinham ou estavam cursando mestrado e apenas $2,4 \%$ tinham ou estavam cursando doutorado (23). Na presente pesquisa, a maioria era especialista. Miranda et al (24) revelam, em estudo realizado sobre perfil de atuação de nutricionistas, que, apesar da expansão das áreas de atuação, há uma permanência nas chamadas "áreas clássicas" (Nutrição Clínica e Unidade de Alimentação e Nutrição) no ranking de maiores atuações, mas confirma, em menores proporções, que as atuações em áreas recém surgidas estão aumentando tanto com o tempo quanto com a região estudada. 
Nesse aspecto, é importante mapear os novos campos de atuação/especialização do trabalho do nutricionista que vem surgindo no Brasil. E, nessa linha, o CFN, em 2016, iniciou a pesquisa nacional a fim de traçar o perfil do nutricionista neste país, mas tais dados ainda não estavam disponíveis até o mês de outubro de 2017.

Registros da ANVISA (25) classificam a Garcínia cambogia (Tamarindo de Malabar) na categoria de moduladores do apetite. Já a Camellia sinensis (chá verde) tem sido utilizada para efeito na perda de peso (26). Algumas condições clínicas para as quais prescrevem fitoterápicos, informadas pelas entrevistadas, corroboram com dados acima mencionados, bem como com estudos sobre efeitos terapêuticos de plantas medicinais em determinadas patologias, Cynara scolymus L (alcachofra) e Plectranthus barbatus Andrews (Boldo) para doenças no fígado e problemas digestivos (27).

Na temática 1: Peculiaridades que motivam ou desmotivam a prescrição fitoterápica, os relatos apontam uma dificuldade em prescrever fitoterápicos devido à ausência de disciplinas que abordem a fitoterapia.

Esse fato também foi mencionado por profissionais de saúde de uma Unidade de Saúde Básica (USB) da cidade de Juiz de Fora, onde a maioria alegava que, durante a graduação, não foi abordado o tema sobre plantas medicinais e Fitoterapia ou, quando houve alguma discussão, foi insuficiente para agregar conhecimento científico (2).

Tal carência tem sido modificada, com a inclusão do tema em disciplinas optativas, na grade curricular das instituições de Ensino Superior em Nutrição, agregando, até mesmo na grade, como disciplina obrigatória, recomendação que já havia sido determinada desde 2013 por meio do Artigo 3 da Resolução 525/2013 do CFN (28).

Haja vista a inserção de temas voltados para os fitoterápicos, associa-se a importância de reformulações na formação dos profissionais de saúde como fortalecimento de conteúdo (29).

Embora tenha sido alegado pouco conhecimento sobre o tema, algumas das pesquisadas informaram realizar prescrição em fitoterapia desde que haja evidência científica.

Esse embasamento também foi mencionado pela equipe do Programa de Fitoterapia do Município de Foz do Iguaçu, ao selecionar algumas plantas medicinais que apresentavam segurança e eficácia comprovadas na literatura (30).

Uma alegação mencionada pelas participantes para prescrever fitoterápicos ou plantas medicinais é o fato de eles proporcionarem resultados satisfatórios, dando credibilidade ao produto. As frases aludidas corroboram com um estudo efetuado com profissionais de saúde de Unidade Básica de Cascavel, no qual eles descreveram várias justificativas, tais como: acreditarem que as plantas têm poder de cura e preferirem utilizar produtos naturais por terem menos efeitos colaterais, quando questionados sobre a possibilidade de serem prescritas plantas medicinais nas USB em substituição aos medicamentos industrializados (9).

$\mathrm{Na}$ temática 2: Importância de especialização para prescrever fitoterápicos com segurança, foi verificada, no diálogo das entrevistadas, a necessidade de mais estudos para prescrever com segurança, bem como ter conhecimento sobre as resoluções do Conselho Federal de Nutrição sobre a prescrição de fitoterápicos pelos nutricionistas.

O Conselho Federal de Nutrição recomenda aos nutricionistas a capacitação necessária para a prática dessa atividade devido à complexidade da prescrição fitoterápica e a opção pelo uso das plantas in natura (11).

Na resolução 525/2013, essa necessidade é reforçada, indicando que "a competência para a prescrição de plantas medicinais, drogas vegetais é atribuída ao nutricionista sem especialização, enquanto a competência para prescrição de fitoterápicos e de preparações magistrais é atribuída exclusivamente ao nutricionista portador de título de 
especialista ou certificado de pós-graduação lato sensu nessa área, sendo exigido o cumprimento do disposto no caput do artigo após três anos de vigência dessa Resolução" (28).

Já a Resolução 556/2015 (31) altera as Resoluções no 416, de 2008, e nº 525, de 2013, e acrescenta disposições à regulamentação da prática da Fitoterapia para o nutricionista como complemento da prescrição dietética, a citar:

\begin{abstract}
Art. $3^{\circ} \mathrm{O}$ exercício das competências do nutricionista para a prática da Fitoterapia como complemento da prescrição dietética deverá observar que: I. a prescrição de plantas medicinais e chás medicinais é permitida a todos os nutricionistas, ainda que sem título de especialista; II. a prescrição de medicamentos fitoterápicos, de produtos tradicionais fitoterápicos e de preparações magistrais de fitoterápicos, como complemento de prescrição dietética, é permitida ao nutricionista desde que seja portador do título de especialista em Fitoterapia, observado o disposto no $\S 4^{\circ}$ deste artigo.
\end{abstract}

A capacitação torna-se importante não apenas como valorização do conhecimento. Em Pernambuco, por meio de buscas em sites, encontram-se opções (no mínimo duas) de cursos para os profissionais se especializarem.

No mercado de trabalho, é indiscutível que um curso de Pós-graduação enriquecerá muito o currículo de um profissional, independentemente da área que pretenda atuar uma vez que a experiência e o aprendizado obtidos nos bancos das universidades já estão longe de ser suficientes para garantir o posicionamento dos profissionais no mercado de trabalho (32).

Ao serem questionadas sobre que sentimentos eram despertados nelas diante dessa atribuição, foram reveladas diversas sensações envolvendo os itens "segurança/insegurança e outras inquietações", surgindo a temática 3: Sentimentos frente à prescrição de fitoterápicos.

A exigência do mercado atual pela busca de profissionais cada vez mais competentes, atualizados e preparados para agir cresce quando surgem novas funções. Num contexto de reações diante de uma atribuição, antes não realizada, uma série de sentimentos e emoções aos quais as pessoas estão sujeitas pode ser revelada, dentre eles ansiedade, receio, cautela e insegurança, conforme verificado nos diálogos. Dados de um estudo, realizado com nutricionistas no âmbito da Saúde Pública, revelaram que cargas laborais, as quais muitas vezes esses profissionais são submetidos, ocorrem com predominância no âmbito mental e psicoafetivas em relação às físicas, destacando-se a ansiedade, o medo, o sentimento de desânimo e de impotência (33).

Muitas vezes, há uma confusão conceitual entre sentimentos e emoções, pois são dois processos que se relacionam, no entanto são diferentes entre si (34). "O que distingue essencialmente sentimento de emoção é: enquanto o primeiro é orientado para o interior, a segunda é eminentemente exterior; ou seja, o indivíduo experimenta a emoção, da qual surge um "efeito" interno, o sentimento" (35). O que também os difere é que os sentimentos são mais duradouros, menos "explosivos" e não são acompanhados de reações orgânicas (36).

Regularmente, as pessoas sabem que suas emoções são mistas, e, embora haja tendência a pensar nisso como exceções, a ambivalência pode ser a regra (37). Essa ambivalência, em relação aos sentimentos, foi verificada no diálogo de uma das entrevistadas.

A temática 4: Perspectivas da Fitoterapia na visão do nutricionista surgiu a partir do interesse em saber sobre a visão das entrevistadas no que diz respeito a essa atividade. A percepção de algumas pesquisadas é que se trata de uma boa ferramenta de trabalho, que toda nutricionista deveria usar, mas com responsabilidade. 
A área da nutrição vem ampliando o campo de atuação profissional devido ao aprimoramento de pesquisas científicas que buscam embasar a utilização empírica de fitoterápicos. Essa habilidade foi legitimada por meio da resolução 402/2007(11), revogada pela resolução 525/2013 do CFN(28).

Esse cenário promissor já era apontado por Ferro (38) com relatos sobre avanços na área científica que levaram ao desenvolvimento de fitoterápicos seguros e eficazes. Salienta-se que, nos países em desenvolvimento, entre eles o Brasil, bem como nos países desenvolvidos, a partir da segunda metade das décadas de 70 e 80 , já ocorria um crescimento das "medicinas alternativas", entre elas, a fitoterapia (39).

Uma concepção de confiabilidade é mencionada por Barreto (2) em um estudo com profissionais da área de saúde engajados com a fitoterapia e dedicados ao projeto de implantação em suas Unidades no âmbito do SUS, no qual os pesquisados relatam que tal empenho passa para a população adscrita uma confiança e credibilidade sobre o uso das plantas medicinais e medicamentos fitoterápicos.

Os diálogos revelam o quanto essa habilidade conferida aos nutricionistas amplia e enriquece práticas profissionais no novo campo de saber, mas gerando ainda anseios para alguns deles. Reflete também uma necessidade de realizar apropriação do tema por parte dessa categoria. Numa perspectiva geral, a população pode sair beneficiada quanto à indicação e/ou prescrição de plantas medicinais e fitoterápicos por esse grupo e por outros especialistas, como recurso terapêutico, legalmente autorizados pelos seus Conselhos.

Nesse contexto, torna-se ainda necessária a divulgação de informações sobre plantas medicinais e fitoterápicos para garantir o uso seguro e racional (40).

Essa prática tende a interagir com a Política Nacional de Práticas Integrativas e Complementares no SUS, que, com a aprovação da Política de Plantas Medicinais e Fitoterápicos (Decreto $\mathrm{n}^{\circ} 5.813$ de 22 de junho de 2006), traz uma expectativa de integralidade da atenção à saúde com garantia e eficácia dos fitoterápicos (41).

\section{Conclusões}

A procura por tratamentos com fitoterápicos e plantas medicinais tem crescido nos últimos anos e o profissional de nutrição integra o grupo dos profissionais aptos a prescrevê-los desde a aprovação da resolução $\mathrm{N}^{\circ}$ 402/2007, implantada pelo CFN, a qual permite que o nutricionista tenha total autonomia para prescrever esses produtos quando julgar necessário.

Percebe-se que integrantes do grupo estudado não se sentem preparados para prescrever com segurança. Os dados sugerem uma possível confusão no que concerne a prescrever, com base nas resoluções do CFN, e indicar fitoterápicos/ plantas medicinais/ drogas vegetais, de modo a demonstrar pouca nitidez quanto à adequada prescrição na prática.

A realização de mais estudos voltados para a prescrição de fitoterápicos pelos nutricionistas torna-se importante, pois investigará, após o conhecimento e aprovação de resoluções mais recentes, a prática, adequação e percepção desses profissionais.

Esse estudo mostrou-se relevante, pois, além de caracterizar alguns nutricionistas que prescrevem fitoterápicos, revelou as condições clínicas associadas a essas recomendações, bem como desvelou os sentimentos de alguns profissionais diante dessa atividade.

Ainda assim, acredita-se que o entendimento desses profissionais sobre fitoterapia no campo da nutrição, bem como suas opiniões, na atualidade, sejam bem diferentes da realidade na época dessa pesquisa, daí a relevância da realização de pesquisas voltadas para esse tema e área de atuação. 
Limitações: Por se tratar de pesquisa qualitativa, o número amostral pequeno (embora suficiente para o modelo) descreve apenas um grupo reduzido, não sendo possível verificar a realidade de outros profissionais inclusive os que concluíram a graduação recentemente e que poderiam já sair com uma "bagagem” de conhecimento maior sobre fitoterápicos.

\section{Referências}

1. Almeida ER. Plantas medicinais brasileiras. São Paulo: Hemus; 1993.

2. Barreto BB. Fitoterapia na Atenção Primária à Saúde: a visão dos profissionais envolvidos. [Dissertação]. Juiz de Fora (MG): Universidade Federal de Juiz de Fora, 2011.

3. Alves LF. Produção de Fitoterápicos no Brasil: História, Problemas e Perspectivas. Rev. Virtual Quim. 2013; 5 (3): 450-513.

4. Silva BQ, Hahn SR. Uso de plantas medicinais por indivíduos com Hipertensão arterial sistêmica, Diabetes mellitus ou Dislipidemias. R. Bras. Farm. Hosp. Serv. Saúde São Paulo 2011; 2 (3): 36-40.

5. Pontes RMF, Monteiro OS, Rodrigues MCS. O uso da fitoterapia no cuidado de crianças atendidas em um centro de saúde do Distrito Federal. Comun. Ciênc. Saúde. 2006; 17(2): 129-139.

6. Santos RL, Guimarães GP, Nobre MSC, Portela AS. Análise sobre a fitoterapia como prática integrativa no Sistema Único de Saúde. Rev. bras. plantas med.(Botucatu) 2001; 13(4): 486-491.

7. Cañigueral S, Vila R. Fitoterapia: vademecum de prescripción. Barcelona: Masson; 2000.

8. Agência Nacional de Vigilância Sanitária. (Brasil). Formulário de Fitoterápicos da Farmacopéia Brasileira / Agência Nacional de Vigilância Sanitária. Brasília: Anvisa, 2011.

9. Tomazzoni MI. Subsídios para a introdução do uso de fitoterápicos na rede básica de saúde do município de Cascavel / PR [Dissertação] Cascavel (PR): Universidade Federal do Paraná, 2004.

10. Balbino EE, Dias MF. Farmacovigilância: um passo em direção ao uso racional de plantas medicinais e fitoterápicos. Rev. Bras. Farmacognosia 2010; 20(6): 992-1000.

11. Conselho Federal de Nutricionistas. Resolução CFN No 402/2007: Regulamenta a prescrição fitoterápica pelo nutricionista de plantas in natura frescas, ou como droga vegetal nas suas diferentes formas farmacêuticas, e dá outras providências. [citado em 2014 out. 7]. Disponível em: http://www.cfn.org.br/eficiente/sites/cfn/pt-br/site.php?secao=resolucoes.

12. Ministério da Saúde. (Brasil). Secretaria de Atenção à Saúde. Departamento de Atenção Básica. Política Nacional de Práticas Integrativas e Complementares no SUS - PNPIC-SUS /Ministério da Saúde, Secretaria de Atenção à Saúde, Departamento de Atenção Básica. - Brasília: Ministério da Saúde, 2006. [citado em 2014 dez.1]. Disponível em: http://bvsms.saude.gov.br/bvs/publicacoes/pnpic.pdf.

13. Brasil. Portaria no 971 de 3 de maio de 2006. Aprova a Política Nacional de Práticas Integrativas e Complementares (PNPIC) no Sistema Único de Saúde. Brasília, 2006 [citado em 2014 dez.1]. Disponível em: http://dtr2001.saude.gov.br/sas/PORTARIAS/Port2006/GM/GM-971.htm.

14. Meirelles AM, Gonçalves CA. Projetos e relatórios de pesquisa em administração. São Paulo: Atlas, 2004.

15. Minayo MCS. O desafio do conhecimento: pesquisa qualitativa em saúde. $9^{a}$ ed. São Paulo: Hucitec, 2006.

16. Costa AMN. O Campo da pesquisa qualitativa e o Método de Explicitação do Discurso Subjacente (MEDS). Psicologia Reflexão e Crítica (Porto Alegre) 2007; 20(001): 65-73.

17. Turato ER. Métodos qualitativos e quantitativos na área de saúde: definições, diferenças e seus objetos de pesquisa. Rev. Saúde Pública. (Campinas). 2005; 39 (3):507-14.

18. Biernacki P, Waldorf D. Snowball sampling: problems and techniques of chain referral sampling. Sociological Methods \& Research, Thousand Oaks, CA 1981; 10(2): 141-163.

19. Baldin N, Munhoz EMB. Educação Ambiental Comunitária: uma Experiência com a Técnica de Pesquisa snowball (Bola de Neve) Rev. eletrônica Mestr. Educ. Ambient. 2011; 27: 46-60.

20. Ministério da Saúde. (Brasil). Conselho Nacional de Saúde. Comissão Nacional de Ética em Pesquisa. Resolução $\mathrm{n}^{\circ}$ 196, de 10 de outubro de 1996: diretrizes e normas regulamentadoras de pesquisa envolvendo seres humanos. Brasília: (DF); 1996. 
21.___. (Brasil). Conselho Nacional de Saúde. Comissão Nacional de Ética em Pesquisa. Resolução no 466, de 12 de dezembro de 2012. Brasília, 2012. [citado em 2014 nov. 2]. Disponível em: http://conselho.saude.gov.br/resolucoes/2012/Reso466.pdf.

22. Bardin L. Análise de Conteúdo. Lisboa: Edições 70, 1977.

23. Conselho Federal de Nutricionistas. Inserção profissional dos nutricionistas no Brasil. Brasília: CFN; 2006. [citado em 2014 out. 7]. Disponível em: http://www.cfn.org.br/novosite/pdf/pesquisa.pdf.

24. Miranda DEGA, Pereira CHC, Paschoini TB, Quaglio T. O perfil de atuação dos ex-alunos do curso de nutrição de uma universidade do interior paulista. Investigação (Franca) 2010; 10: 54-59.

25. Agência Nacional de Vigilância Sanitária. (Brasil). Resolução RDC nº 88 de 16 de março de 2004. Dispõe sobre a Lista de referências bibliográficas para avaliação de segurança e eficácia de fitoterápicos. Diário Oficial da União. Brasília, 2004 [citado em 2014 out.8]. Disponível em: http://www.anvisa.gov.br/medicamentos/registro/legis.htm.

26. Correia CÉ, Santos JM, Ribeiro PLB. Uso de Fitoterápicos no Tratamento da Obesidade: Uma Revisão de Literatura. 25 p - TCC (Pós Graduação de Nutrição Clínica e Esportiva) Pontifícia Universidade Católica de Goiás, Goiás, 2012.

27. Badke MR, Budó MLD, Silva FM, Ressel LB. Plantas Medicinais: O saber sustentado na prática do cotidiano popular. Esc Anna Nery (impr.) 2011; 15 (1):132-139.

28. Conselho Federal de Nutrição. Resolução CFN N ${ }^{\circ} 525 / 2013$. Regulamenta a prática da fitoterapia pelo nutricionista, atribuindo-lhe competência para, nas modalidades que especifica, prescrever plantas medicinais, drogas vegetais e fitoterápicos como complemento da prescrição dietética e, dá outras providências. [citado em 2014 set. 17]. Disponível em: http://www.cfn.org.br/eficiente/repositorio/legislacao/resolucoes/583.pdf

29. Pinheiro ARO, Recine E, Alencar B, Fagundes AA, Sousa JS, Monteiro RA, Toral N. Percepção de professores e estudante em relação ao perfil de formação de nutricionista em saúde pública. Rev. Nutr. (Campinas). 2012; 25(5): 631-643.

30. Bruning MCR, Mosegui GBG, Vianna CMM. A utilização da fitoterapia e de plantas medicinais em unidades básicas de saúde nos municípios de Cascavel e Foz do Iguaçu - Paraná: a visão dos profissionais de saúde. Ciênc. saúde coletiva, (Rio de Janeiro), 2012; 17 (10): 2675-2685.

31. Conselho Federal de Nutrição. Resolução CFN N 556/2015. Altera as Resoluções no 416, de 2008, e $\mathrm{n}^{\circ}$ 525, de 2013, e acrescenta disposições à regulamentação da prática da Fitoterapia para o nutricionista como complemento da prescrição dietética. [citado em 2017nov 04]. Disponível em: http://www.cfn.org.br/wp-content/uploads/resolucoes/Res 556_2015.htm.

32. Instituto Brasileiro de Educação e Gestão (IBEG). A importância da Pós Graduação. [citado em 2014 nov 25]. Disponível em: http://ibeg.org.br/2013/01/05/a-importancia-da-pos-graduacao/.

33. Bosi MLM. Trabalho e Subjetividade: Cargas e Sofrimento na Prática da Nutrição Social. Rev. Nutr. 2000; 13(2): 107-115

34. Lopes RB. As Emoções. Psicologado. 2011. [citado em 2014 nov 2]. Disponível em: https://psicologado.com/psicologia-geral/introducao/as-emocoes.

35. Damásio A. O Sentimento de Si. Tradução de M.F.M. Revista pelo autor. Porto. Europa-América, 2000.

36. Bock AMB, Furtado O, Teixeira MLT. Psicologias: uma introdução ao estudo de psicologia. $14^{\mathrm{a}}$ ed. São Paulo: Saraiva, 2008.

37. Davidoff LL. Introdução à Psicologia. $3^{\mathrm{a}}$ ed. São Paulo: Perason Makron Books, 2001.

38. Ferro D. Fitoterapia: conceitos clínicos. São Paulo: Atheneu; 2008.

39. Luz MT. Cultura contemporânea e medicinas alternativas: novos paradigmas em saúde no fim do século XX. Physis 1997; 7(1):13-43.

40. Macedo JAB. Plantas medicinais e fitoterápicos na atenção primária à saúde: contribuição para profissionais prescritores. Monografia (Especialização). Rio de Janeiro, 2016.

41. Ministério da Saúde (Brasil). Secretaria de Ciência, Tecnologia e Insumos Estratégicos. Departamento de Assistência Farmacêutica. Política nacional de plantas medicinais e fitoterápicos / Ministério da Saúde, Secretaria de Ciência, Tecnologia e Insumos Estratégicos, Departamento de Assistência Farmacêutica. - Brasília: Ministério da Saúde, 2006. 